\title{
Hydrophobic silica nanoparticle-stabilized invert emulsion as drilling fluid for deep drilling
}

\author{
Maliheh Dargahi-Zaboli $^{1} \cdot$ Eghbal Sahraei $^{1} \cdot$ Behzad Pourabbas $^{2}$
}

Received: 15 September 2015/Published online: 19 December 2016

(C) The Author(s) 2016. This article is published with open access at Springerlink.com

\begin{abstract}
An oil-based drilling fluid should be stable and tolerant to high temperatures for use in deep drilling. An invert emulsion of water in oil is a good choice as an oilbased drilling fluid which is a mixture of a solid phase and two immiscible liquid phases stabilized by a polymeric surfactant. In deep drilling, due to high temperatures, the polymeric surfactant degrades and a phase separation occurs. Here, octadecyltrimethoxysilane-modified silica nanoparticles were used to form a stable invert emulsion of water in oil for the drilling fluid model which resulted in a milky fluid with the formation of $60 \mu \mathrm{m}$ water droplets. In addition, rheological study showed that using hydrophobic silica nanoparticles resulted in a stable water in oil invert emulsion with desired properties for a drilling fluid that can be modified by adjusting the nanoparticle nature and content. Aging experiments at $120{ }^{\circ} \mathrm{C}$ indicated that they also have good stability at high temperatures for challenging drilling operations.
\end{abstract}

Keywords Deep drilling · Drilling fluid model · Hightemperature aging $\cdot$ Rheology $\cdot$ Silica nanoparticles · Stable invert emulsion

Eghbal Sahraei

sahraei@sut.ac.ir

1 Department of Chemical Engineering, Petroleum Research Center, Sahand University of Technology, Tabriz, Iran

2 Department of Polymer Engineering, Nanostructured Materials Research Center, Sahand University of Technology, Tabriz, Iran

Edited by Yan-Hua Sun

\section{Introduction}

Drilling technology has been widely used in the applied sciences and engineering, such as manufacturing industries, petroleum industries, pharmaceutical industries, aerospace, research laboratories, and from small-scale laboratories to heavy industry (Hossain and Al-Majed 2015). Modern drilling fluid (also called drilling mud) is an essential part of the rotary drilling system. The successful completion of a hydrocarbon well and its cost depend on the properties of drilling fluids to some extent (Bourgoyne et al. 1986; Hossain and Al-Majed 2015). Therefore, the selection of a suitable drilling fluid and routine control of its properties are the concern of the drilling operations (Hossain and AlMajed 2015).

During oil and gas well drilling, the drilling fluid is used to (1) clean the borehole by carrying drilling cuts to the surface, (2) create sufficient hydrostatic pressure against the subsurface formation pressure, (3) keep the drilled borehole open for cementing casings in the hole, and (4) cool and lubricate the rotating bit (Bourgoyne et al. 1986). Therefore, to suspend the drilling cuts and keep the suspension when the circulation is stopped, the base fluid of the drilling fluid such as water or oil should be thickened to obtain a high viscosity. Furthermore, a drilling fluid must be nontoxic and stable during drilling as well as being low cost. To have all desired properties, a drilling fluid as a complex fluid includes different types of additives (Agarwal et al. 2013; Bourgoyne et al. 1986; Coussot et al. 2004; Shah et al. 2010). The type and amount of additives depend on the drilling requirements and the type of reservoir to be drilled and bring particular properties and rheological behavior for the drilling fluid. Drilling fluids are often described as thixotropic shear-thinning fluids with a yield stress which could be modified according to the flow and 
shear conditions (Agarwal et al. 2013; Coussot et al. 2004; Shah et al. 2010).

Oil-based drilling fluids such as an invert emulsion of water in an oil phase with various additives and waterbased drilling fluids such as aqueous mixtures of clays and polymers are the two main categories of drilling fluid. Since the water-based fluids are relatively less expensive, they are more common, but their applications are limited to relatively low-temperature and low-pressure drilling operations. In the case of high-temperature and high-pressure drilling operations, diesel, fuel oil, mineral oil, or a linear paraffin are generally used as the base fluid in the oil-based fluids (Coussot et al. 2004; Shah et al. 2010; Agarwal et al. 2013).

In high-temperature drilling conditions $\left(120\right.$ and $225{ }^{\circ} \mathrm{C}$ in some cases), the oil-based drilling fluids are favored because of better thermal stability and being less affected by contaminants which results in faster drilling. Oil-based drilling fluids are composed of oil as the continuous phase and water as the dispersed phase in conjunction with emulsifiers, viscosity modifiers, weighting materials, and wetting agents. Organophilic clays and barite are common viscosity modifiers and weighting material, respectively. In deep drilling, due to high temperatures, polymeric surfactants degrade and phase separation occur; therefore, an emulsifier tolerant of high temperatures is needed (Coussot et al. 2004; Shah et al. 2010; Agarwal et al. 2013). Also, the current trend in the drilling fluid development is to come up with novel environmentally friendly drilling fluids that will rival oil-based drilling fluids in terms of low toxicity level, performance, efficiency, and cost (Hossain and Al-Majed 2015). Therefore, nanosilica, nanographene, and other nano-based materials have been proposed for use as alternative drilling fluid additives. Nanomaterials in drilling fluid systems are expected to reduce the total solids and/or chemical content of such drilling fluid systems and hence to reduce the overall cost of drilling fluid system development (Hossain and Al-Majed 2015).

Silica nanoparticles (NPs) as an inorganic oxide are environmentally friendly nanoparticles, with a wide variety of industrial applications, in food and pharmaceuticals, catalysis, ceramics, and also as a stabilizer of emulsions. They are a good option for stabilizing the invert emulsion (Vignati and Piazza 2003; Dickinson 2010). Modified silica NPs are used as emulsifiers besides the commonly used surfactant molecules to stabilize an emulsion system by preventing the coalescence of droplets. This depends on the hydrophobicity of nanoparticles. These particle-stabilized emulsions are known as Pickering emulsions (Aveyard et al. 2003; Agarwal et al. 2013; Binks and Rodrigues 2003; Binks and Whitby 2005). In a Pickering emulsion, particles absorb on the liquid-liquid interface and the contact angle that particles make with the oil-water interface (measured into the aqueous phase) determines the interface energy of attachment, tending to stabilize emulsions (Aveyard et al. 2003; Agarwal et al. 2013; Binks and Rodrigues 2003, 2005; Binks and Whitby 2005).

Since microparticles and nanoparticles of various shapes, sizes, and surface characteristics are commercially available; in early work Agarwal et al. (2011) used commercial hydrophobic nanosilica and organically modified bentonite clay for imparting stability to invert emulsions used as drilling fluids. Also, in the next work of Agarwal et al. (2013), formation of a stable invert emulsion using a combination of commercial hydrophobic nanosilica and organically modified nanoclay was documented while the rheology and morphology were examined (Agarwal et al. 2013).

The main objective of this study is to maintain morphology and rheological properties of oil-based drilling fluid while meeting the requirements of high-temperature operation. For first time, octadecyltrimethoxysilane (OTMOS)-modified core-shell silica NPs, synthesized by the authors, were used as the only emulsifier to stabilize the invert emulsion of water in oil (poly 1-decene) as a drilling fluid model. In addition, the rheological properties and morphology of the prepared stable invert emulsion were investigated, and the best model for prediction of flow behavior, yield stress, and plastic viscosity was determined.

\section{Theoretical concepts}

Emulsions are a common form of material in which emulsifiers, low molar mass surfactants, and surface-active polymers are used as stabilizers to help disperse one phase in the other. Less well-known stabilizers are solid particles, without forming micelles, and hence, solubilization phenomena are not present (Aveyard et al. 2003; Binks et al. 2005; Binks and Lumsdon 2000; Ding et al. 2005; Melle et al. 2005; Pickering 1907).

A proper formulation of an emulsion should be stable against droplet coalescence and macroscopic phase separation. In 1907, Pickering observed that colloidal particles situated at the oil-water interface can also stabilize emulsions of oil and water which are called either Pickering emulsions or solid-stabilized emulsions (Pickering 1907). Stabilization is achieved when nanometer to micrometer-sized particles diffuse to the interface between the dispersed and continuous phases and remain there in a stable mechanical equilibrium, forming rigid structures and minimizing coalescence. In a Pickering emulsion, the contact angle $\theta_{\text {ow }}$ in which the particle makes with the interface and shows the relative position of the particles at the oil-water interface (Fig. 1) is a critical parameter and specifies the type of emulsion, either water in oil (W/O) or 
(a)

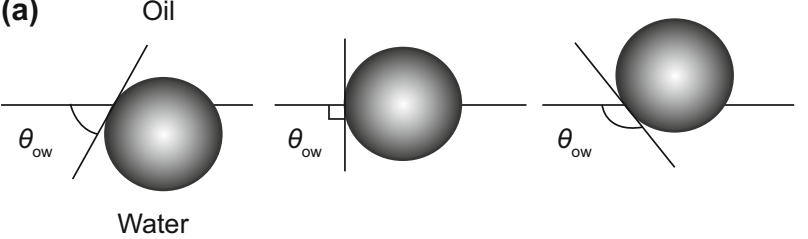

(b)

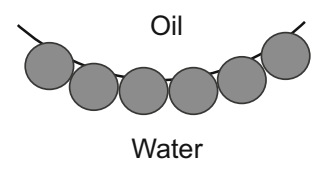

Fig. 1 a Position of a small spherical particle at a planar oil-water interface for a contact angle (measured through the aqueous phase) less than $90^{\circ}$ (left), equal to $90^{\circ}$ (center), and greater than $90^{\circ}$ (right). b Corresponding probable positioning of particles at a curved interface. For $\theta_{\mathrm{ow}}<90^{\circ}$, solid-stabilized $\mathrm{O} / \mathrm{W}$ emulsions may form (left). For $\theta_{\text {ow }}>90^{\circ}$, solid-stabilized $\mathrm{W} / \mathrm{O}$ emulsions may form (right)

oil in water (O/W) (Aveyard et al. 2003; Binks and Lumsdon 2000; Binks et al. 2005; Ding et al. 2005; Melle et al. 2005; Pickering 1907).

For hydrophilic particles, e.g., metal oxides, the contact angle $\theta_{\text {ow }}$ measured through the aqueous phase is normally less than $90^{\circ}$ while a larger fraction of the particle surface is located in water than in oil. For hydrophobic particles, e.g., suitably modified silica, the contact angle $\theta_{\text {ow }}$ is generally greater than $90^{\circ}$, and the particles reside more in oil than in water. Particles which are either too hydrophilic or too hydrophobic are likely to be dispersed in either the aqueous or oil phase, respectively, resulting very unstable emulsions (Aveyard et al. 2003; Binks and Lumsdon 2000; Binks et al. 2005; Ding et al. 2005; Effati and Pourabbas 2012; Melle et al. 2005; Xue et al. 2009; Pickering 1907). Another way to determine the hydrophobic nature of particles is to measure the contact angle of a water drop on a surface covered with the nanoparticles, $\theta$, and is exact enough to be applied in present work (Binks and Lumsdon 2000; Effati and Pourabbas 2012; Xue et al. 2009). During the formation of an emulsion, hydrophobic particles fabricate a shell around a water droplet. This layer in the interface acts as a capsule to separate water droplets from each other and minimizes the total interfacial energy (Binks 2002; Hsu et al. 2005).

From a practical point of view as the drilling fluid, once the flow of the drilling fluid is stopped for any reason, a desirable drilling fluid should possess a yield stress large enough to prevent the settling of suspended solids, such as drilling cuts and barite particles. However, when the flow is started again, the gel structure should break down quickly in order to minimize the pumping costs during an actual drilling operation (Bourgoyne et al. 1986; Shah et al. 2010).

\section{Experimental}

\subsection{Materials}

OTMOS-modified silica NPs with variety of hydrophobicities (synthesized by authors as summarized in the next section) as concentrated colloid in ethanol (EtOH, $99.9 \%$, Fisher Scientific), methanol (MeOH, $99 \%$, Fisher Scientific), ammonium hydroxide $\left(\mathrm{NH}_{4} \mathrm{OH}, 28 \%-29 \%\right.$, Fisher Scientific), tetraethoxysilane (TEOS, $\geq 98 \%$, SigmaAldrich), octadecyltrimethoxysilane (OTMOS, $\geq 97 \%$, Sigma-Aldrich), and poly(1-decene) (kinematic viscosity $v$ of $50 \mathrm{cSt}$ at $40{ }^{\circ} \mathrm{C}$, Sigma-Aldrich) were used as received without further purification. All other solvents were laboratory grade obtained mainly from Sigma-Aldrich and used as received without further treatments.

\subsection{Synthesis of OTMOS-modified core-shell silica NPs}

Silica NPs were prepared by hydrolysis of TEOS in methanol/ethanol mixtures, similar to the Stöber procedure (Stöber et al. 1968), but with an addition of OTMOS as the surface modifier. All reactions were carried out at $65-70{ }^{\circ} \mathrm{C}$ for $60 \mathrm{~min}$ with a TEOS concentration of $0.25 \mathrm{~mol} / \mathrm{L}$ and a water/TEOS molar ratio of 38 (Effati and Pourabbas 2012). First, an alcohol solution with a volume of $23 \mathrm{~mL}$ was made from a mixture of $\mathrm{EtOH}$ and $\mathrm{MeOH}$ following by adding water and $\mathrm{NH}_{4} \mathrm{OH}$ under vigorous stirring at room temperature. Next, the reaction mixture was heated to appropriate temperature $\left(65-70{ }^{\circ} \mathrm{C}\right)$ under a $\mathrm{N}_{2}$ atmosphere. Then, 1.8-mL TEOS was added to the mixture dropwise. Stirring was continued while adding OTMOS dropwise for 4 min (not all at once) until the desired OTMOS/TEOS molar ratio was reached. At the end of the reaction, precipitated silica NPs were separated by centrifugation at $10,000 \mathrm{rpm}$ and $10{ }^{\circ} \mathrm{C}$ for $15 \mathrm{~min}$. After discarding the supernatant, the particles were dispersed in water and EtOH by sonication. This precipitation was repeated 2 times; finally, the particles were re-dispersed in EtOH up to $10 \mathrm{mg} / \mathrm{mL}$. A typical reaction yielded $500 \mathrm{mg}$ of functionally modified silica NPs with an average diameter below $100 \mathrm{~nm}$. Contact angle $(\theta)$ measurements showed that hydrophilic bare silica NPs $\left(\theta \sim 0^{\circ}\right)$ changed to hydrophobic silica NPs $\left(\theta=92^{\circ}\right.$ and $\left.\theta=115^{\circ}\right)$ just by adding 0.01 and 0.02 molar ratio of OTMOS to TEOS, respectively. 


\subsection{Stabilization of an invert emulsion employing OTMOS-modified silica NPs}

The following assumptions were considered: (1) The continuous phase in invert emulsions is the oil phase of poly 1-decene, (2) the dispersed phase is 30 volume percent deionized water (DI water), (3) to impart emulsion stability, synthesized OTMOS-modified silica NPs are employed.

Invert emulsions were fabricated in several experiments using specific procedures. First, OTMOS-modified silica NPs with different hydrophobicities as concentrated colloids in ethanol were diluted with amounts of water. Next, colloids were added to a specific amount of poly 1-decene to reach $30 \mathrm{vol} \%$ water. Simultaneously, the emulsion was homogenized with a PowerGen homogenizer at 14,000 rpm for 5 min following 20,000 rpm for $2 \mathrm{~min}$. Colloids were added dropwise; otherwise, the dispersion of the water phase in the oil phase is weak and phase separation occurs. A creamy emulsion was formed which showed a stable invert emulsion and was used for morphology and rheology analysis. Before rheology measurements, all samples were kept under pre-shear of $850 \mathrm{~s}^{-1}$ for $1 \mathrm{~h}$ to create a shear history following by a 10 -min rest. After that, in terms of mathematically representing the flow behavior, yield stress, and plastic viscosity, mathematical models including the Bingham plastic, Power law, Casson, and Herschel-Bulkley were considered to find the best fit (Agarwal et al. 2011; Hossain and Al-Majed 2015; Gupta 2000; Shah et al. 2010).

Finally, due to importance of high-temperature aging of the invert emulsion, an aging experiment was done at $120^{\circ} \mathrm{C}$. This was carried out using a 500-mL Fann aging cell pressurized to 4 atmospheres by nitrogen gas to prevent the evaporation of water contained in the invert emulsion. For aging under static conditions, the pressurized cell was placed in a preheated oven for $12 \mathrm{~h}$. Next, the aged drilling fluids were depressurized and cooled to room temperature following by homogenizing at $20,000 \mathrm{rpm}$ for 2 min. To compare results with Agarwal et al. $(2011,2013)$ study, some experiments were done at $225^{\circ} \mathrm{C}$ and at 3.5 MPa (Agarwal et al. 2011, 2013).

\subsection{Characterization}

Measurements of contact angle, $\theta$, were done using a laboratory-made contact angle instrument equipped with a camera. The films with OTMOS-modified silica NPs were prepared by a doctor blade coating process at $78{ }^{\circ} \mathrm{C}$ (around boiling point of EtOH) using $10 \mathrm{mg} \mathrm{mL}^{-1}$ OTMOS-modified silica NPs/ethanol solution on a glass slide. The average contact angle of $2 \mu \mathrm{L}$ of DI water droplets, placed on the coated glass, was calculated by measuring the same sample at ten different positions at room temperature in a clean room (Xue et al. 2009; Effati and Pourabbas 2012).
Droplet sizes of the dispersed water phase in emulsions were determined from images from an optical microscope equipped with a camera. Since the emulsions were quite concentrated to characterize morphology, they were diluted by a factor of 20 with additional poly 1-decene as the oil phase. Then, a droplet of the diluted emulsion was placed on a slide for microscopy work.

The rheological properties of the invert emulsion were determined with the help of an AR 2000 EX Rheometer (TA Instruments, New Castle, DE) fitted with parallel plate fixtures. The diameter of each plate was $4 \mathrm{~cm}$, and the gap was set at $1 \mathrm{~mm}$ for all the experiments. All measurements were taken at room temperature.

\section{Results and discussion}

\subsection{Morphology of the emulsions}

It has been found that hydrophobic silica NPs can be used to stabilize W/O emulsions (Aveyard et al. 2003; Binks and Whitby 2005; Binks et al. 2008). To judge the stability, the time taken for the emulsions to separate out into two phases was considered.

Figure 2 shows the effect of hydrophobicity of silica NPs on emulsion properties for an overall nanoparticle concentration of $2 \mathrm{wt} \%$. In the case of the emulsions containing extremely hydrophilic or hydrophobic silica NPs (Fig. 2a, d-f), phase separation occurred after only a few minutes. By contrast, the emulsions containing the modified silica NPs with contact angles around $92^{\circ}$ (Fig. 2b) and $115^{\circ}$ (Fig. 2c) were stable for months and days, respectively.

Number-average droplet sizes of the dispersed phase for the prepared emulsions shown in Table 1 were determined from optical microscopy images in Fig. 3. From Table 1, it can be seen that the finest dispersed phase size is $60 \mu \mathrm{m}$

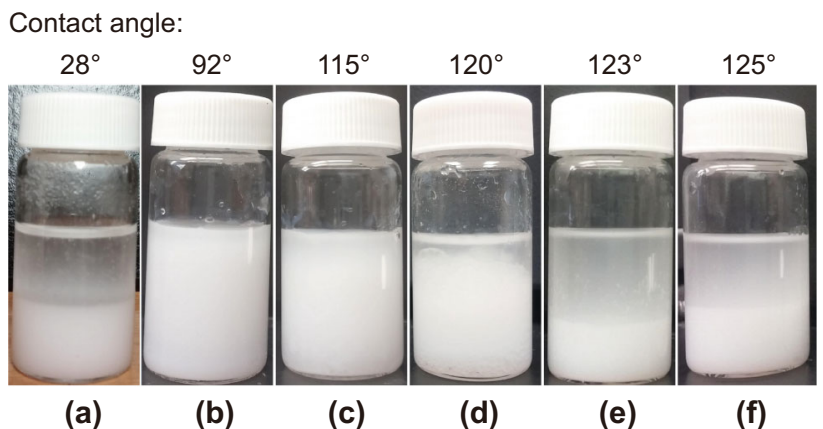

Fig. 2 Photographs of invert emulsions stabilized by silica NPs at an overall particle concentration of $2 \mathrm{wt} \%, 5 \mathrm{~min}$ after preparation at different OTMOS to TEOS molar ratios. a Bare silica NPs; b 0.01; c 0.02 ; d 0.03 ; e 0.04 ; f 0.05 OTMOS to TEOS molar ratio 
Table 1 Average water droplet sizes in various invert emulsions stabilized by silica NPs

\begin{tabular}{lll}
\hline Emulsions (30 vol\% water) $)^{\mathrm{a}}$ & Diameter, $\mu \mathrm{m}$ & Emulsion status \\
\hline Stabilized by $1 \mathrm{wt} \%$ of $0.01^{\mathrm{b}}$ OTMOS-modified silica NPs, $\theta=92^{\circ}$ & $100-200$ & Stable for days \\
Stabilized by $2 \mathrm{wt} \%$ of $0.01^{\mathrm{b}}$ OTMOS-modified silica NPs, $\theta=92^{\circ}$ & $\sim 60$ & Stable for weeks and months \\
Stabilized by $1 \mathrm{wt} \%$ of $0.02^{\mathrm{b}}$ OTMOS-modified silica NPs, $\theta=115^{\circ}$ & $\sim 200$ & Stable for days \\
Stabilized by $2 \mathrm{wt} \%$ of $0.02^{\mathrm{b}}$ OTMOS-modified silica NPs, $\theta=115^{\circ}$ & $\sim 100$ & Stable for days
\end{tabular}

${ }^{a}$ The nanoparticle content reported here is on the basis of oil

b OTMOS to TEOS molar ratio
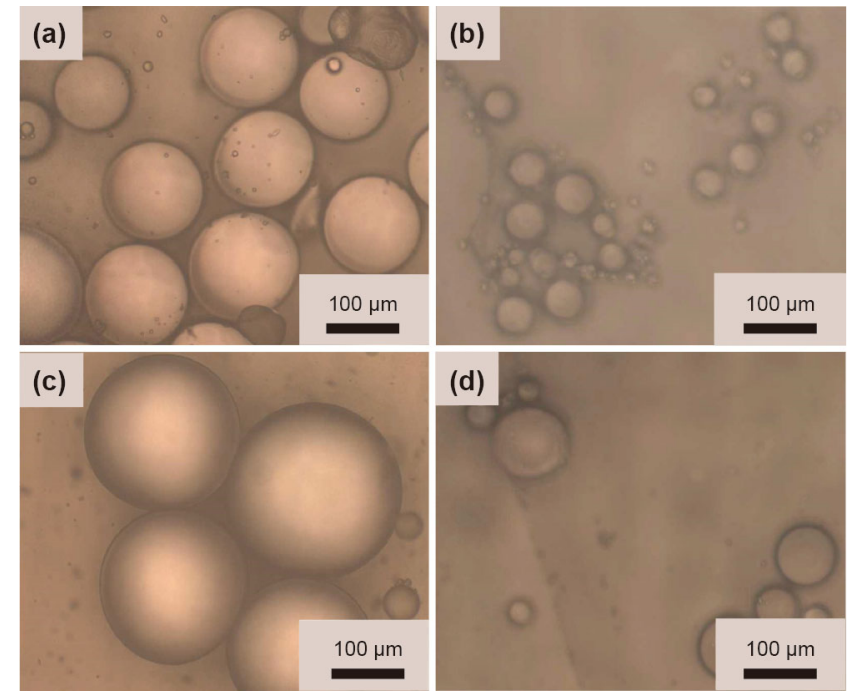

(d)

Fig. 3 Morphology of invert emulsions containing 30 vol\% water stabilized by 1 wt $\%$ (a) and 2 wt $\%$ (b) of modified silica NPs with an OTMOS/TEOS molar ratio of 0.01 , respectively; and $1 \mathrm{wt} \%$ (c) and $2 \mathrm{wt} \%$ (d) of modified silica NPs with an OTMOS/TEOS molar ratio of 0.02 , respectively

which resulted in the emulsion stabilized by OTMOSmodified silica NPs, which was synthesized with an OTMOS to TEOS molar ratio of 0.01 and contact angle $92^{\circ}$.

\subsection{Flow behavior}

The flow behavior of the emulsions described in Table 1 is shown in Figs. 4 and 5. For all cases, the shear-thinning behavior observed was appropriate for a drilling fluid. It was found that the addition of OTMOS-modified silica NPs to the invert emulsion resulted in at least a doubling of viscosity at high shear rates and as much as one order of magnitude increase in viscosity at low shear rates in the case of using $2 \mathrm{wt} \%$ silica NPs (Binks et al. 2005). This desirable behavior of the invert emulsion is a consequence of a network structure which formed by NPs. In the case of the silica NPs synthesized with 0.01 OTMOS to TEOS molar ratio, there was a modest enhancement in viscosity when the addition amount of OTMOS-modified silica NPs increased from $1 \mathrm{wt} \%$ to $2 \mathrm{wt} \%$ (black line and red line in Fig. $4\left(\theta=92^{\circ}\right.$ in Table 1$)$, and using more than $2 \mathrm{wt} \%$ of NPs did not change the viscosity significantly. In all cases, except perhaps when using $1 \mathrm{wt} \%$ silica NPs synthesized with 0.02 OTMOS to TEOS molar ratio which resulted in a contact angle of $115^{\circ}$, very high viscosity at low shear stress can be achieved. Figure 5 also showed that the point of transition from high viscosity to low viscosity was sharp, and the shear stress level could be altered over a modest range by changing the hydrophobicity and the amount of the added nanoparticles. Also considering stability of emulsions in Table 1, the invert emulsion stabilized by $2 \mathrm{wt} \%$ exhibited the best results among all prepared invert emulsions.

\subsection{Mathematical modeling}

By considering the shear-thinning behavior of the invert emulsions, the Bingham plastic, power law, Casson model, and Herschel-Bulkley model shown in Eqs. (1)-(4) were 


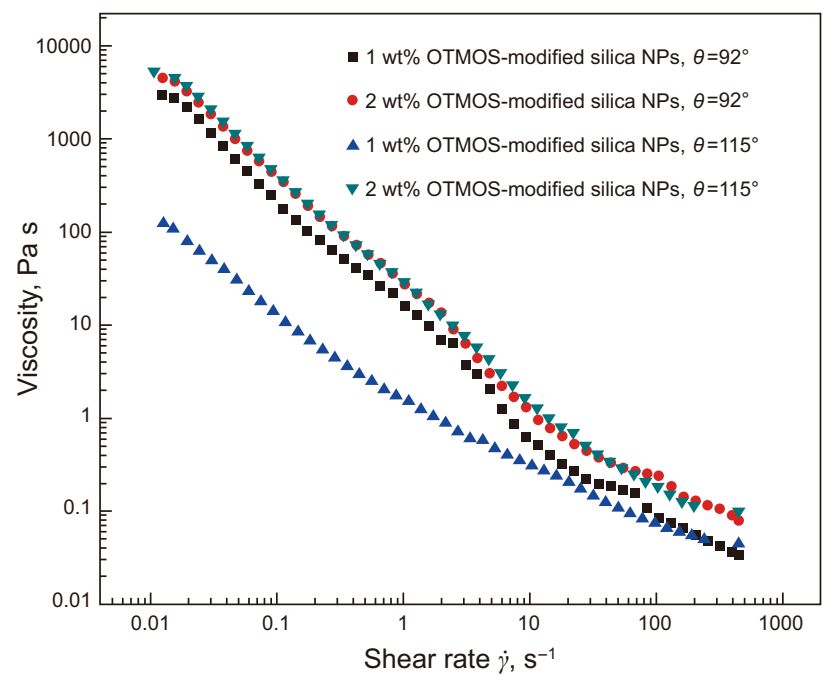

Fig. 4 Measured viscosity versus shear rate of invert emulsions containing 30 vol\% water stabilized by OTMOS-modified silica NPs

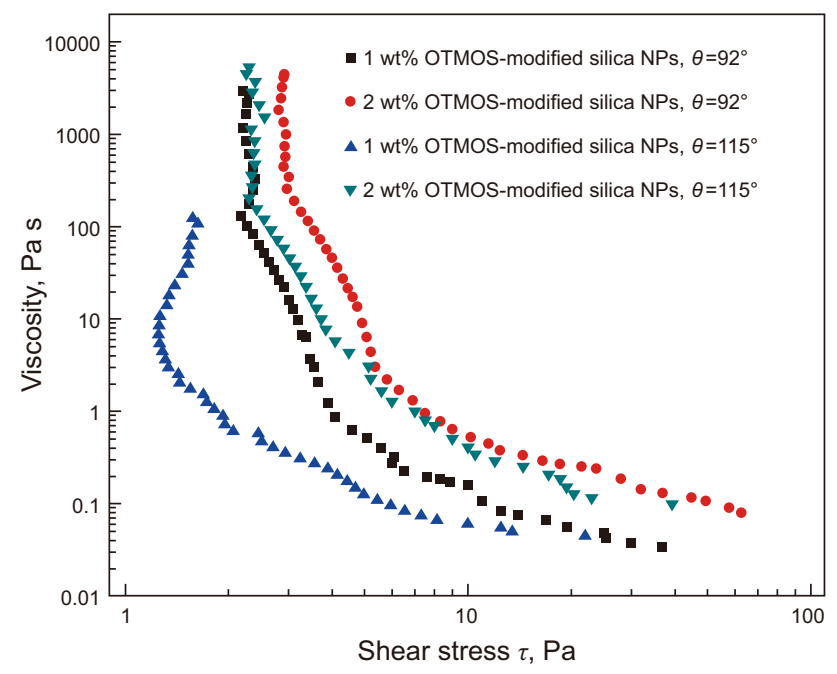

Fig. 5 Measured viscosity versus shear stress of invert emulsions containing $30 \mathrm{vol} \%$ water stabilized by OTMOS-modified silica NPs

considered to predict the flow behavior (Agarwal et al. 2011, 2013; Livescu 2012; Hossain and Al-Majed 2015).

$\tau=\tau_{0}+\eta_{\infty} \dot{\gamma}$

$\tau=\eta_{\infty} \dot{\gamma}^{n}$

$\sqrt{\tau}=\sqrt{\tau_{0}}+\sqrt{\eta_{\infty} \dot{\gamma}}$

$\tau=\tau_{0}+\eta_{\infty} \dot{\gamma}^{n}$

where $\tau$ is the shear stress; $\dot{\gamma}$ is the shear rate; $\tau_{0}$ and $\eta_{\infty}$ are the model constants representing the yield stress and the plastic viscosity, respectively; and $n$ is the power-law index.

According to the patterns between shear stress and shear rate which are shown in Eqs. (1)-(4), flow curves (shear stress vs shear rate) were drawn on both linear and logarithmic scales, and also, square root of shear stress versus shear rate was drawn on linear scale in Figs. 6, 7, and 8.

As shown in Fig. 6, the Bingham model shown in Eq. (1) is not a good model because the obtained figures are in the form of curves instead of straight lines. Similarly in Fig. 7, on the log scale, it can be said that the power-law model shown in Eq. (2) is not suitable, too. Since the data plotted in Fig. 6 follow the HerschelBulkley model shown in Eq. (3), this model could be considered as a desirable model for predicting shear-thinning behavior of the invert emulsion presented here. Also, according to the Casson model pattern shown in Eq. (4), the measured data are plotted in Fig. 8. Data plot nearly linearly in Fig. 8, which shows that the Casson model can be used to fit the behavior of the invert emulsions as well as the Herschel-Bulkley model. Since the Herschel-Bulkley model and Casson model were selected to predict the flow behavior, the validation of the models seemed to consist of nothing more than quoting the $R^{2}$ statistic from the fit. A linear regression was used to obtain the parameters of models using Figs. 9 and 10. The measured parameters of the Herschel-Bulkley model and the Casson model are shown in Table 2.

It is found that in the Casson model, the yield stress and the plastic viscosity vary over a modest range depending on the nature and amount of nanoparticles used, and the plastic viscosity has a negligible amount in comparison with the Herschel-Bulkley model. In the Herschel-Bulkley model, the changes of the shear stress are more than the Casson model, and the plastic viscosity is almost constant in the case of OTMOS-modified silica NPs with a contact angle of $115^{\circ}$ (Agarwal et al. 2011, 2013).

Neither the Casson model nor the Herschel-Bulkley model predicts the experimental data perfectly, and the Herschel-Bulkley model is a complicated three-parameter model. The Casson model was found to provide the best fit for the data.

It is worth mentioning that depending on the requirements of a drilling operation, the viscosity can change from water-like values of around $0.001 \mathrm{~Pa} \mathrm{~s}$ to several folds higher. Similarly, the yield stress may range from being negligible to more than $10 \mathrm{~Pa}$. The viscosity, yield stress, and other properties of the drilling fluid depend on the composition and could be tuned as required (Agarwal et al. 2011, 2013).

\subsection{Barite effect}

Barite as the weighting agent is used to impart density to all types of drilling fluids. Weighting agents are used to control formation pressures and prevent formation damage or blowup (Bourgoyne et al. 1986; Hossain and Al-Majed 


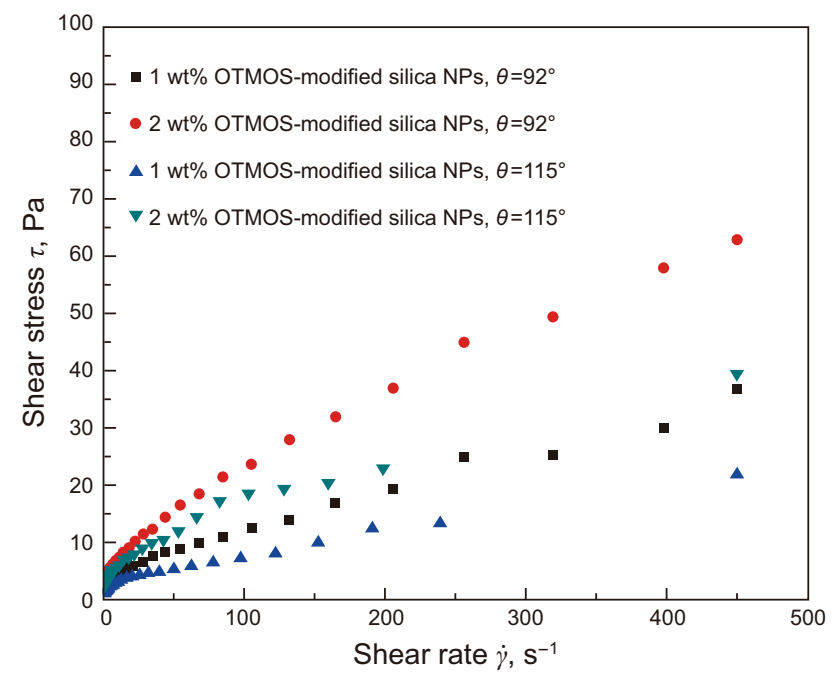

Fig. 6 Measured shear stress versus shear rate of invert emulsions containing $30 \mathrm{vol} \%$ water stabilized by OTMOS-modified silica NPs, linear scale

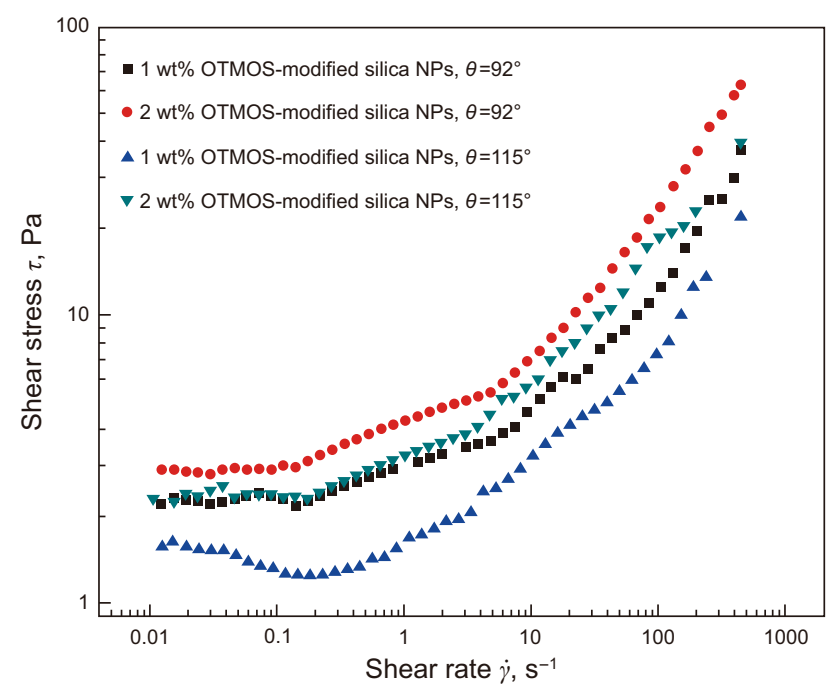

Fig. 7 Measured shear stress versus shear rate of invert emulsions containing 30 vol\% water stabilized by OTMOS-modified silica NPs, logarithmic scale

2015). In this work, API-grade barite was used to prepare drilling fluids with a density of $1.40 \mathrm{~g} \mathrm{~mL}^{-1}$ (equal to $90 \mathrm{lb} \mathrm{ft}^{3}$ ) from the unweighted fluid of $0.89 \mathrm{~g} \mathrm{~mL}^{-1}$. The required amount of barite was added to the prepared OTMOS-modified silica NPs-stabilized emulsion, and the mixture was then homogenized for $2 \mathrm{~min}$. Figure 11a shows flow curves of drilling fluids with and without barite. It can be seen that in the case of using barite, the yield stress decreased significantly while the plastic viscosity was mostly unaffected (Table 3). This occurs because that the gel structure formed by NPs is disrupted by the microsized particles of barite. However, if the content of the OTMOS-modified silica NPs increased from $2 \mathrm{wt} \%$ to

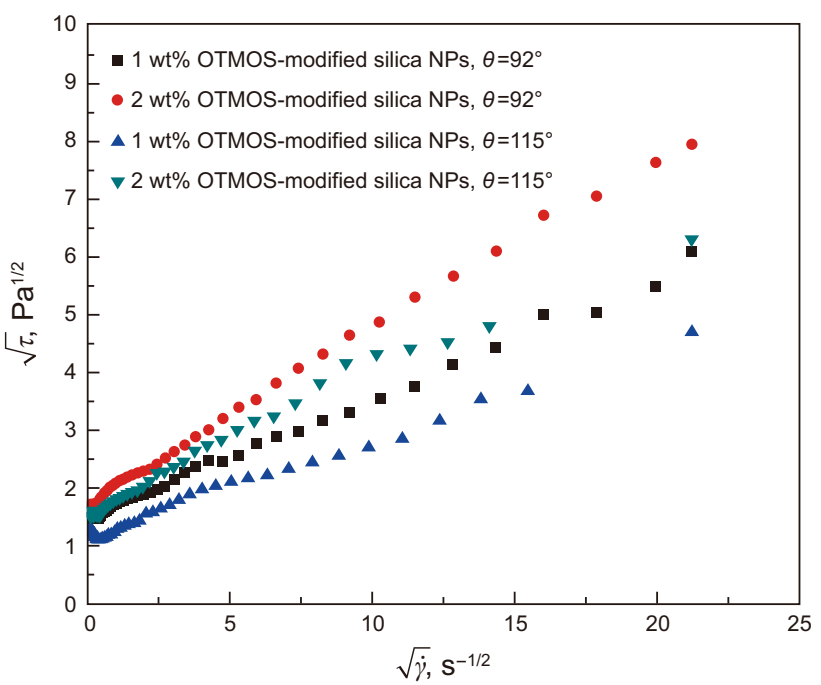

Fig. 8 Measured square root of shear stress versus square root of shear rate of invert emulsions containing $30 \mathrm{vol} \%$ water stabilized by OTMOS-modified silica NPs, linear scale

$3 \mathrm{wt} \%$, the yield stress also increased, which shows that the flow properties would be adjusted by changing the amount of nanoparticles to achieve the desired properties. As in the case without barite, the flow behavior can be predicted by the Casson model (Fig. 11b). Table 3 presents the parameters of the Casson model.

\subsection{High-temperature aging effect}

The invert emulsion prepared here which was stabilized by the OTMOS-modified silica NPs can be used as drilling fluid when it has good wellbore stability and high-temperature tolerance. In ultra-deep drilling, surfactants degrade due to high temperature, causing a phase separation (Agarwal et al. 2011, 2013). Figure 12 shows the optical microscopy image of the invert emulsion stabilized by OTMOS-modified silica NPs with a contact angle of $92^{\circ}$ and aged at $120^{\circ} \mathrm{C}$ for $12 \mathrm{~h}$. As can be seen, the water phase was still emulsified as small droplets in the oil phase and less than $80 \mu \mathrm{m}$. Also, some experiments were done at $225{ }^{\circ} \mathrm{C}$ to compare results with work done by Agarwal et al. $(2011,2013)$.

Flow curves in Figs. 13a and 14a show similar behavior for the fresh invert emulsion. The parameters of the Casson model for the aged emulsion (in Table 4) show that the yield stress and the plastic viscosity reduced. As in other cases, the Casson model properly predicted the aged invert emulsion behavior (Figs. 13b, 14b). The reduced yield stress value indicates that the aged invert emulsion could not form a gel structure effectively. This behavior of yield stress is similar to the invert emulsion prepared by Agarwal et al. $(2011,2013)$ in which nanosilica and nanoclay were used as solid additives (Agarwal et al. 2011, 2013). Similar 

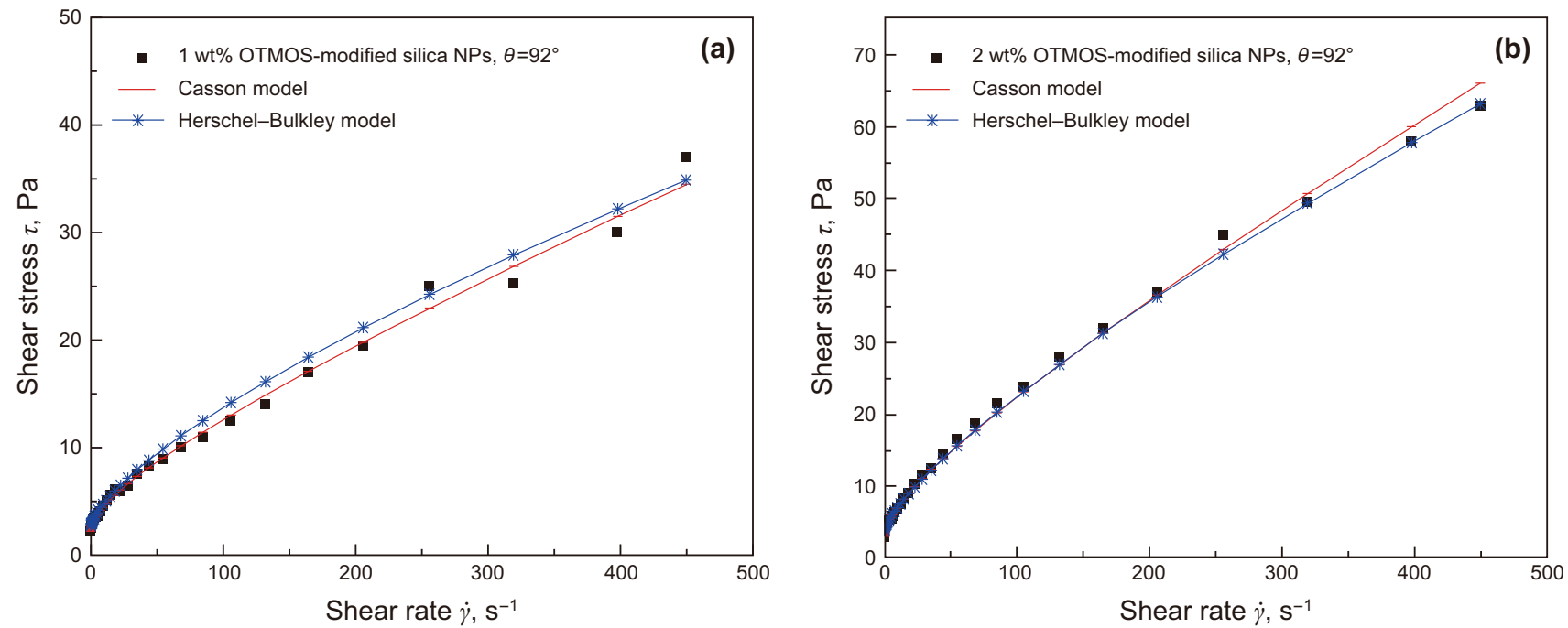

Fig. 9 Shear stress versus shear rate of invert emulsions containing 30 vol\% water stabilized by 1 wt $\%$ OTMOS-modified silica NPs $\left(\theta=92^{\circ}\right)$ (a) and $2 \mathrm{wt} \%$ OTMOS-modified silica NPs $\left(\theta=92^{\circ}\right)(\mathbf{b})$. The solid lines without and with stars represent the best fit of the Casson model and the Herschel-Bulkley model, respectively. Parameters of models are given in Table 2
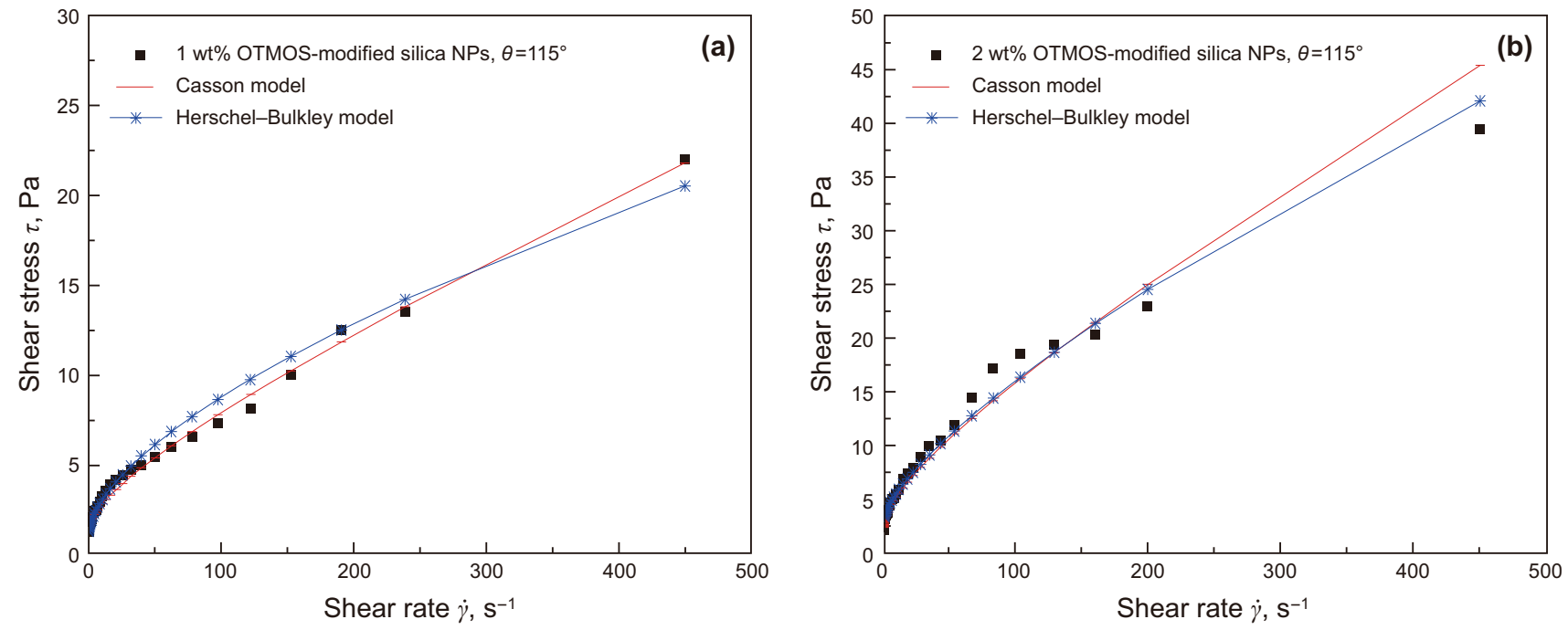

Fig. 10 Shear stress versus shear rate of invert emulsions containing $30 \mathrm{vol} \%$ water stabilized by 1 wt $\%$ OTMOS-modified silica NPs $\left(\theta=115^{\circ}\right)(\mathbf{a})$ and $2 \mathrm{wt} \%$ OTMOS-modified silica NPs $\left(\theta=115^{\circ}\right)(\mathbf{b})$. The solid lines without and with stars represent the best fit of the Casson model and the Herschel-Bulkley model, respectively. Parameters of models are given in Table 2

Table 2 Parameters of models for emulsions containing OTMOS-modified silica NPs

\begin{tabular}{|c|c|c|c|c|c|c|c|}
\hline \multirow[t]{2}{*}{ Invert emulsion (30 vol\% water) } & \multicolumn{3}{|c|}{ Casson model } & \multicolumn{4}{|c|}{ Herschel-Bulkley model } \\
\hline & $\tau_{0}, \mathrm{~Pa}$ & $\eta_{\infty}, \mathrm{Pa} \mathrm{s}$ & $R^{2}$ & $\tau_{0}, \mathrm{~Pa}$ & $\eta_{\infty}, \mathrm{Pa} \mathrm{s}$ & $n$ & $R^{2}$ \\
\hline Stabilized by $1 \mathrm{wt} \%$ of 0.01 OTMOS-modified silica NPs, $\theta=92^{\circ}$ & 2.2 & 0.043 & 0.9942 & 2.7 & 0.42 & 0.71 & 0.9870 \\
\hline Stabilized by $2 \mathrm{wt} \%$ of 0.01 OTMOS-modified silica NPs, $\theta=92^{\circ}$ & 2.9 & 0.092 & 0.9974 & 4.0 & 0.52 & 0.78 & 0.9968 \\
\hline Stabilized by 1 wt $\%$ of 0.02 OTMOS-modified silica NPs, $\theta=115^{\circ}$ & 1.3 & 0.028 & 0.9946 & 1.3 & 0.41 & 0.63 & 0.9836 \\
\hline Stabilized by 2 wt $\%$ of 0.02 OTMOS-modified silica NPs, $\theta=115^{\circ}$ & 2.4 & 0.060 & 0.9739 & 3.5 & 0.42 & 0.74 & 0.9779 \\
\hline
\end{tabular}



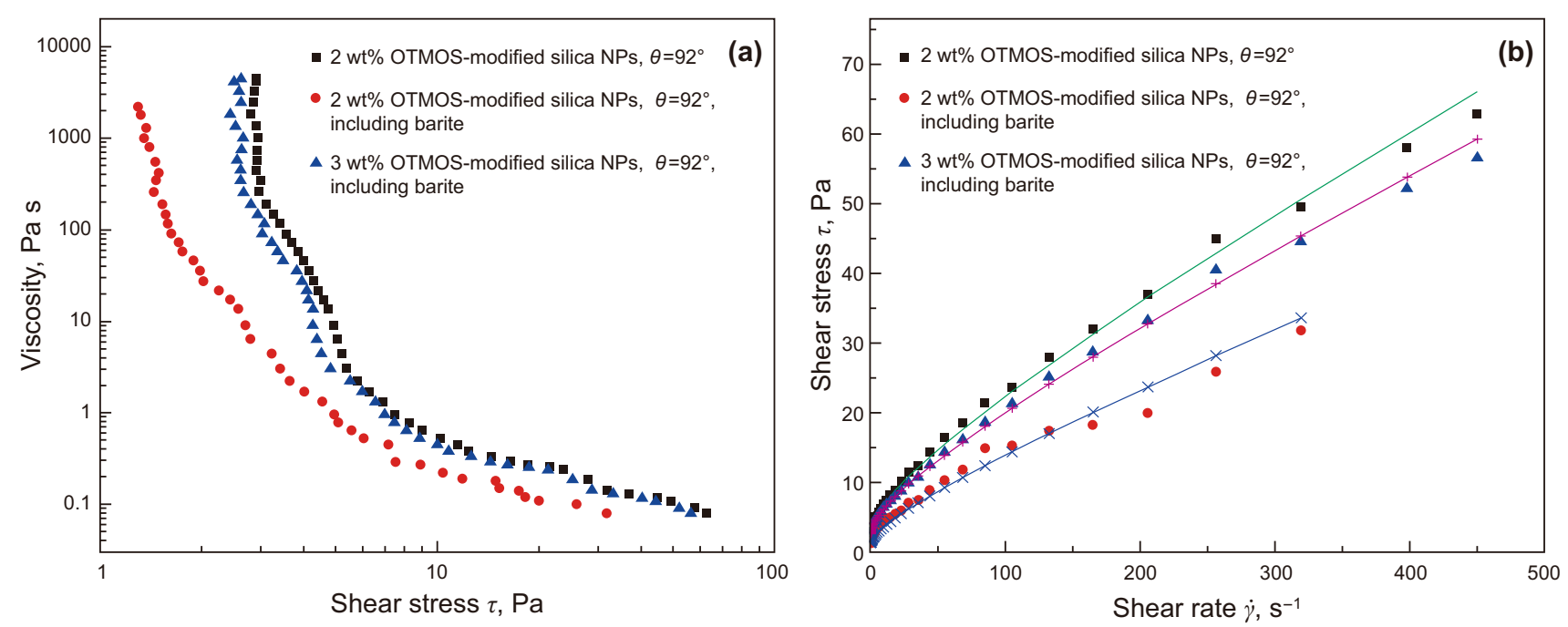

Fig. 11 Effect of barite on the flow behavior of invert emulsions containing 30 vol\% water stabilized by OTMOS-modified silica NPs $\left(\theta=92^{\circ}\right)$. a Viscosity versus shear stress. b Shear stress versus shear rate. The solid lines represent the best fit of the Casson model. Model parameters are given in Table 3

Table 3 Parameters of the Casson model for emulsions containing OTMOS-modified silica NPs and barite

\begin{tabular}{llr}
\hline Invert emulsion (30 vol\% water) & \multicolumn{2}{l}{ Casson model } \\
\cline { 2 - 3 }$\tau_{0}, \mathrm{~Pa}$ & $\eta_{\infty}, \mathrm{Pa} \mathrm{s}$ & 0.092 \\
\hline Stabilized by $2 \mathrm{wt} \%$ of 0.01 OTMOS-modified silica NPs, $\theta=92^{\circ}$ & 2.90 & 0.9974 \\
Stabilized by $2 \mathrm{wt} \%$ of 0.01 OTMOS-modified silica NPs, $\theta=92^{\circ}$, containing barite & 1.25 & 0.069 \\
Stabilized by $3 \mathrm{wt} \%$ of 0.01 OTMOS-modified silica NPs, $\theta=92^{\circ}$, containing barite & 2.60 & 0.082 \\
\hline
\end{tabular}

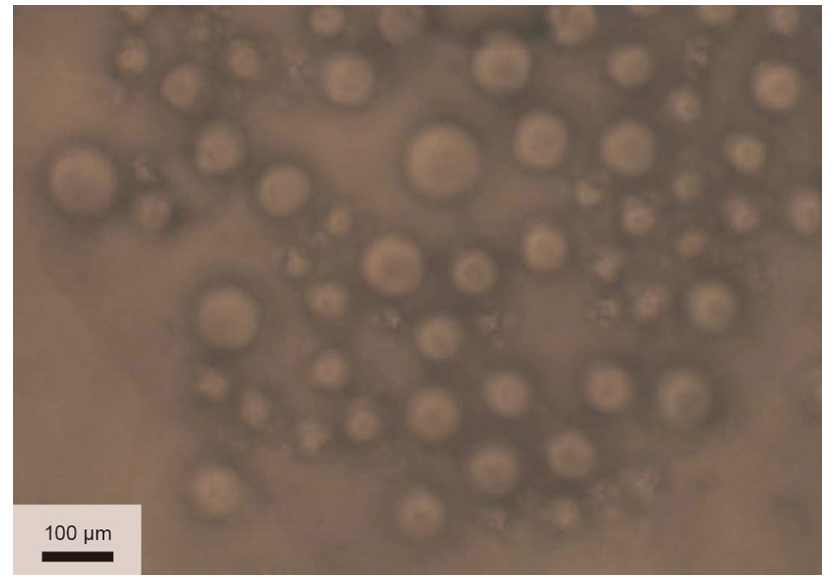

Fig. 12 Morphology of the invert emulsion stabilized by $2 \mathrm{wt} \%$ OTMOS-modified silica NPs $\left(\theta=92^{\circ}\right)$ after aging at $120^{\circ} \mathrm{C}$

to the yield stress, the plastic viscosity reduced after aging and did not follow the invert emulsion prepared by Agarwal et al. (2011, 2013). This adverse behavior can be explained by the nanoclay platelets available in Agarwal study which resulted in better exfoliation and dispersion of the nanoclay platelets by the heat treatment (Agarwal et al. 2011, 2013).

\section{Conclusions}

Synthesized functionally modified silica NPs as the only emulsifier were used to emulsify and stabilize the invert emulsion employing water and poly 1-decene oil phase. It was shown that the resulting morphology and flow behavior of the prepared invert emulsion meet drilling fluid requirements.

The flow behavior of the invert emulsions was investigated as a function of amount and nature of silica NPs, and it was found that the shear-thinning behavior could be represented by the Casson and Herschel-Bulkely models and the best results belong to $2 \mathrm{wt} \%$ OTMOS-modified silica NPs which make a $92^{\circ}$ contact angle. On adding a weighting material of barite, there was a loss of the yield stress, but this could be recovered by increasing the content of OTMOS-modified silica NPs. 

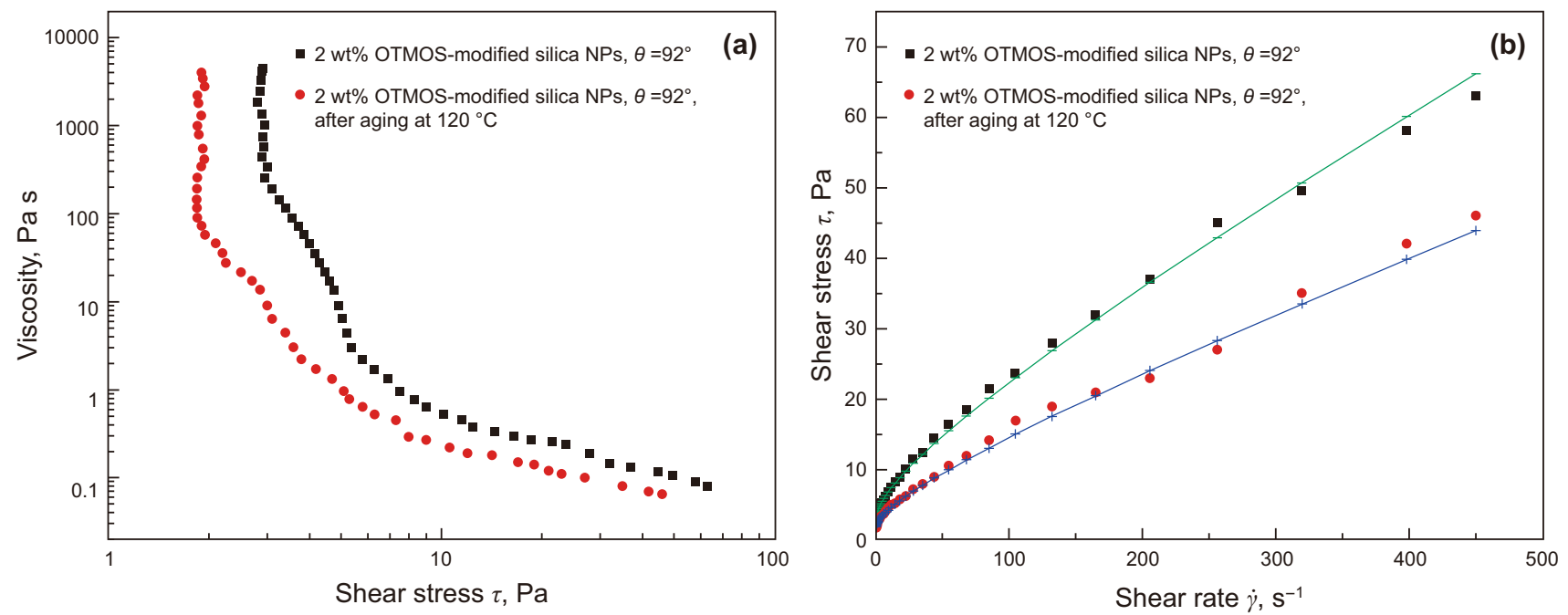

Fig. 13 Flow behavior of invert emulsions containing 30 vol\% water stabilized by OTMOS-modified silica NPs $\left(\theta=92^{\circ}\right)$ before and after aging at $120{ }^{\circ} \mathrm{C}$. a Viscosity versus shear stress. b Shear stress versus shear rate. The solid lines represent the best fit of the Casson model. Model parameters are given in Table 4
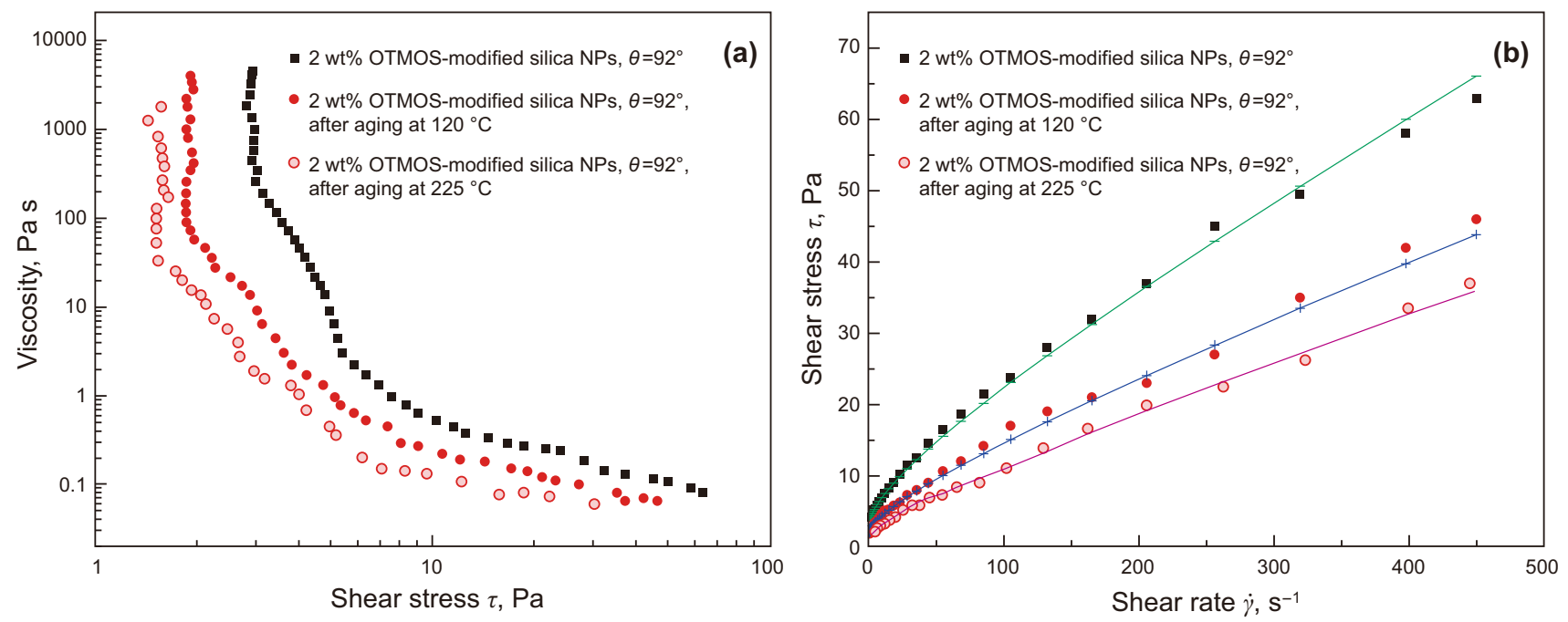

Fig. 14 Flow behavior of invert emulsions containing 30 vol\% water stabilized by OTMOS-modified silica NPs $\left(\theta=92^{\circ}\right)$ before and after aging at $225{ }^{\circ} \mathrm{C}$. a Viscosity versus shear stress. b Shear stress versus shear rate. The solid lines represent the best fit of the Casson model. Model parameters are given in Table 4

Table 4 Parameters of the Casson model for fresh/aged emulsions containing OTMOS-modified silica NPs

\begin{tabular}{|c|c|c|c|}
\hline \multirow[t]{2}{*}{ Invert emulsion (30 vol\% water) } & \multicolumn{3}{|c|}{ Casson model } \\
\hline & $\tau_{0}, \mathrm{~Pa}$ & $\eta_{\infty}, \mathrm{Pa} \mathrm{s}$ & $R^{2}$ \\
\hline Stabilized by $2 \mathrm{wt} \%$ of 0.01 OTMOS-modified silica NPs, $\theta=92^{\circ}$, fresh & 2.9 & 0.092 & 0.9974 \\
\hline Stabilized by $2 \mathrm{wt} \%$ of 0.01 OTMOS- modified silica NPs, $\theta=92^{\circ}$, after aging at $120^{\circ} \mathrm{C}$ & 1.7 & 0.063 & 0.9957 \\
\hline Stabilized by $2 \mathrm{wt} \%$ of 0.01 OTMOS- modified silica NPs, $\theta=92^{\circ}$, after aging at $225^{\circ} \mathrm{C}$ & 1.3 & 0.051 & 0.9963 \\
\hline
\end{tabular}


In addition, after aging at 120 and $225^{\circ} \mathrm{C}$ for $12 \mathrm{~h}$, the stabilized invert emulsion maintained its stability and flow properties. Thus, OTMOS-modified silica NPs could be a good candidate as emulsifier instead of other additives such as polymeric ones, especially for formulating drilling fluids at $120^{\circ} \mathrm{C}$ and higher temperatures of drilling operations.

Acknowledgements The authors would like to extend lots of thanks to Mr. Nasser Maragheh, vice president of Sarve Energy Arya Sahand Engineering Company (SEAS Co.) and Dr. Mahmoud Dargahi for their invaluable discussion and advice.

Open Access This article is distributed under the terms of the Creative Commons Attribution 4.0 International License (http://crea tivecommons.org/licenses/by/4.0/), which permits unrestricted use, distribution, and reproduction in any medium, provided you give appropriate credit to the original author(s) and the source, provide a link to the Creative Commons license, and indicate if changes were made.

\section{References}

Agarwal S, Phuoc TX, Soong Y, et al. Nanoparticle-stabilized invert emulsion drilling fluids for deep-hole drilling of oil and gas. Can J Chem Eng. 2013;9(1):1641-9. doi:10.1002/cjce.21768.

Agarwal S, Tran P, Soong Y, et al. Flow behavior of nanoparticle stabilized drilling fluids and effect of high temperature aging. American Association of Drilling Engineers (AADE). 2011; AADE-11-NTCE-3.

Aveyard R, Binks BP, Clint J. Emulsions stabilized solely by colloidal particles. Adv Colloid Interface Sci. 2003;100-102:503-46. doi:10.1016/S0001-8686(02)00069-6.

Binks BP. Particles as surfactants - similarities and differences. Curr Opin Colloid Interface Sci. 2002;7:21-41. doi:10.1016/S13590294(02)00008-0.

Binks BP, Liu W, Rodrigues JA. Novel stabilization of emulsions via the heteroaggregation of nanoparticles. Langmuir. 2008;24:4443-6. doi:10.1021/la800084d.

Binks BP, Lumsdon SO. Influence of particle wettability on the type and stability of surfactant-free emulsions. Langmuir. 2000;16(1):8622-31. doi:10.1021/la000189s.

Binks BP, Philip J, Rodrigues JA. Inversion of silica-stabilized emulsions induced by particle concentration. Langmuir. 2005;21(1):3296-302. doi:10.1021/la046915z.

Binks BP, Rodrigues JA. Types of phase inversion of silica particle stabilized emulsions containing triglyceride oil. Langmuir. 2003;19:4905-12. doi:10.1021/la020960u.
Binks BP, Rodrigues JA. Inversion of emulsions stabilized solely by ionizable nanoparticles. Angew Chem Int Ed. 2005;44:441-4. doi:10.1002/anie.200461846.

Binks BP, Whitby CP. Nanoparticle silica-stabilised oil-in-water emulsions: improving emulsion stability. Colloids Surf A Physicochem Eng Asp. 2005;253(1):105-15. doi:10.1016/j. colsurfa.2004.10.116.

Bourgoyne AT, Millheim KK, Chenevert ME, et al. Applied drilling engineering. 1st ed. SPE textbook series; 1986.

Coussot P, Bertrand F, Herzhaft B. Rheological behavior of drilling muds, characterization using MRI visualization. Oil Gas Sci Technol - Rev IFP. 2004;59(1):23-9. doi:10.2516/ogst:2004003.

Dickinson E. Food emulsions and foams: stabilization by particles. Eur Curr Opin Colloid Interface Sci. 2010;15:40-9. doi:10.1016/ j.cocis.2009.11.001.

Ding A, Binks BP, Goedel WA. Influence of particle hydrophobicity on particle-assisted wetting. Langmuir. 2005;21:1371-6. doi:10. 1021/la047858c.

Effati E, Pourabbas B. One-pot synthesis of sub-50 nm vinyl- and acrylate-modified silica nanoparticles. Powder Technol. 2012;219:276-83. doi:10.1016/j.powtec.2011.12.062.

Gupta RK. Polymer and composite rheology. 2nd ed. New York: CRC Press; 2000.

Hossain ME, Al-Majed AA. Fundamentals of sustainable drilling engineering. 1st ed. Hoboken: Wiley; 2015.

Hsu MF, Nikolaides MG, Dinsmore AD, et al. Self-assembled shells composed of colloidal particles: fabrication and characterization. Langmuir. 2005;21:2963-70. doi:10.1021/la0472394.

Livescu S. Mathematical modeling of thixotropic drilling mud and crude oil flow in well sand pipelines-a review. J Pet Sci Eng. 2012;98:174-84. doi:10.1016/j.petrol.2012.04.026.

Melle S, Lask M, Fuller GG. Pickering emulsions with controllable stability. Langmuir. 2005;21:2158-62. doi:10.1021/la047691n.

Pickering SU. Emulsions. J Chem Soc Trans. 1907;91:2001-21. doi:10.1039/CT9079102001.

Shah SN, Shanker NH, Ogugbue CC. Future challenges of drilling fluids and their rheological measurements. American Association of Drilling Engineers (AADE). 2010; AADE-10-DF-HO-41.

Stöber W, Fink A, Bohn E. Controlled growth of monodisperse silica spheres in the micron size range. J Colloid Interface Sci. 1968;26:62-9. doi:10.1016/0021-9797(68)90272-5.

Vignati E, Piazza R. Pickering emulsions: interfacial tension, colloidal layer morphology, and trapped-particle motion. Langmuir. 2003;19:6650-6. doi:10.1021/la0342641.

Xue L, Li J, Fu J, et al. Super-hydrophobicity of silica nanoparticles modified with vinyl groups. Colloids Surfaces A Physicochem Eng Asp. 2009;338:15-9. doi:10.1016/j.colsurfa.2008.12.016. 